\title{
Influence of megestrol acetate on nutrition and inflammation in dialysis patients - preliminary results ${ }^{\star}$
}

\author{
Justyna Gołębiewska ${ }^{1,2 凶}$, Monika Lichodziejewska-Niemierko ${ }^{1,2}$, \\ Ewa Aleksandrowicz ${ }^{4}$, Mikołaj Majkowicz ${ }^{3}$, Wiesława Łysiak-Szydłowska ${ }^{4}$ \\ and Bolesław Rutkowski ${ }^{2}$ \\ ${ }^{1}$ Palliative Medicine Department, ${ }^{2}$ Department of Nephrology, Transplantology and Internal Medicine, ${ }^{3}$ Quality \\ of Life Research Department, ${ }^{4}$ Chair of Clinical Nutrition, Medical University of Gdańsk, Gdańsk, Poland
}

Received: 03 July, 2009; revised: 13 November, 2009; accepted: 24 November, 2009

available on-line: 08 December, 2009

\begin{abstract}
Malnutrition is a common clinical problem in dialysis patients. So far the management of malnutrition in this population has not been fully successful. The aim of the study was to evaluate the efficacy and safety of use of megestrol acetate suspension in malnourished dialysis patients. Twenty-six hypoalbuminemic (albumin $\leq 3.8 \mathrm{~g} / \mathrm{dl}$ ) dialysis patients took $160 \mathrm{mg}$ of megestrol acetate daily for a period of two months. Anthropometry (dry weight, body mass index) and biochemical measurements of nutrition (serum albumin, triglycerides, total cholesterol) and inflammation (hsCRP, IL-1 $\beta$, IL-6) were performed on a monthly basis. The treatment led to a statistically significant increase $(P<0.05)$ in anthropometry and albumin concentration, with no statistically significant changes in total cholesterol, triglycerides and indices of inflammation. Side effects included overhydration, diarrhoea and hyperglycaemia. Thus, megestrol acetate may be an effective therapeutic agent in improving the nutritional status of carefully selected dialysis patients, while it might not mitigate inflammation. Because of the prevalent side effects it must be monitored closely.
\end{abstract}

Keywords: malnutrition, megestrol acetate, proinflammatory cytokines

\section{INTRODUCTION}

The number of end-stage renal disease (ESRD) patients is constantly increasing, including the number of patients who require chronic renal replacement therapy. Despite the huge headway that has been made in dialysis techniques and equipment, the symptom burden faced by maintenance dialysis patients remains unacceptably high. Among the most common problems experienced by dialysis patients are anorexia and malnutrition/wasting (Murtagh et al., 2007). Their prevalence varies, depending on the study between $10 \%$ and $75 \%$. Not only is malnutrition a problem because of its negative impact on the quality of life (Dwyer et al., 2002) and the number of comorbidities and hospitalizations but, what is most

\footnotetext{
${ }^{\square}$ Corresponding author: Justyna Gołębiewska, Department of Nephrology, Transplantology and Internal Medicine, Medical University of Gdańsk, Dębinki 7, 80-529 Gdańsk, Poland; tel. (48) 58349 2557; fax (48) 58349 2551; e-mail: jgolebiewska@gumed.edu.pl

^The results were previously presented in part as an abstract at two conferences: XIV International Congress on Nutrition and Metabolism in Renal Disease, Marseilles, France (11-15th June 2008), and XVII Conference of the Polish Society of Nephrology, Poznań, Poland (5-7th June 2008).

Abbreviations: AIDS, acquired immunodeficiency syndrome; BMI, body mass index; CPD, continuous peritoneal dialysis; ESRD, end-stage renal disease; hsCRP, high-sensitivity C-reactive protein; IL-1, interleukin 1; IL-6, interleukin 6; Kt/V, urea clearance over time related to the volume of urea distribution; MHD, maintenance haemodialysis; MIA, malnutrition-inflammation-atherosclerosis; SGA, subjective global assessment; TNF- $\alpha$, tumour necrosis factor alpha.
} 
important, its enormous influence on cardiovascular and all-cause mortality (Kalantar-Zadeh et al., 2001). Therefore, successful management of malnutrition could ameliorate the cardiovascular epidemic and poor outcome in dialysis patients (Kalantar-Zadeh et al., 2003; 2005).

The aetiology of malnutrition in ESRD is complex and may include many underlying factors. Hence, its treatment is difficult. Protein-energy malnutrition often overlaps with inflammation and atherosclerosis leading to malnutrition-inflammationatherosclerosis (MIA) syndrome (Rashid Qureshi et al., 2002; Kalantar-Zadeh et al., 2003). The key role in all these events is played by proinflammatory cytokines such as IL-1, IL-6, and TNF- $\alpha$. That is why, when conventional nutritional and metabolic interventions do not provide satisfactory results, treatment aimed at eliminating or reducing inflammation becomes a necessity. Several new strategies, including the use of megestrol acetate, are under investigation.

Megestrol acetate is a synthetic progestagen that has been demonstrated to increase appetite and weight in patients with cancer or AIDS (Lopez et al., 2004) and is believed to act by down-regulating the proinflammatory cytokines IL-1, IL-6, and TNF- $\alpha$ (Mantovani et al., 1998a; 1998b). Therefore not only could it improve the nutritional status, but also reverse the cytokine-dependent inflammatory process.

So far, only a limited number of studies has been published evaluating the use of megestrol acetate in dialysis patients (Lien \& Ruffenach, 1996; Burrowes et al., 1999; Boccanfuso et al., 2000; Costero et al., 2004; Rammohan et al., 2005; Monfared et al., 2009). These limited but promising studies with variable results, and the successful use of megestrol acetate in cancer and AIDS patients, together with the lack of data regarding the influence of megestrol acetate on inflammation in ESRD patients, support the rationale for conducting a study aimed at evaluating the use of megestrol acetate in dialysis patients. Therefore, the goal of this study was to examine the influence of megestrol acetate (160 mg daily) on nutrition and inflammation in dialysis patients over a period of two months. The dose of $160 \mathrm{mg}$ was chosen as it was reported to be safe, yet efficient.

\section{PATIENTS AND METHODS}

Subject recruitment and study design. A multicenter, prospective study design was used. The study protocol was approved by the Bioethics Committee of the Medical University of Gdańsk (registration number NKEBN/5/2006, issued 24.02.2006).
All procedures were performed in accordance with the Helsinki Declaration.

Between June 2006 and March 2007 maintenance hemodialysis patients (MHD) and chronic peritoneal dialysis (CPD) patients from six hemodialysis facilities (381 patients) and two peritoneal dialysis centres (89 patients) were screened for eligibility. Inclusion criteria were: (1) MHD or CPD for at least 3 months, (2) serum albumin concentration $\leq 3.8 \mathrm{~g} / \mathrm{dl}$ (Bromcresol Green), while exclusion criteria were (1) concurrent use of glucocorticoids and (2) inadequate dialysis as defined by $\mathrm{Kt} / \mathrm{V}$ of $<1.2$ for MHD and $<2.0$ for CPD patients. HIV/AIDS or malignancy were not exclusion criteria. Before enrolment, patients received detailed written and verbal information regarding the aims and protocol of the study. Written informed consent was obtained from all study patients.

At baseline and at monthly intervals anthropometric measurements and biochemical analyses were performed.

Patients were provided with megestrol acetate solution (Megalia, Vipharm) after the baseline measurements and instructed to take $4 \mathrm{ml}(160 \mathrm{mg})$ daily,

Anthropometric indices. These included height, dry weight and body mass index (BMI). BMI was calculated using the following equation: dry weight $(\mathrm{kg})$ : height squared $\left(\mathrm{m}^{2}\right)$.

Biochemical analysis (nutritional and inflammatory indices). Blood sample were drawn from peripheral vein (CPD patients) or from artero-venous fistula or catheter before commencing dialysis (MHD patients). Serum was separated $<30$ min after drawing and stored at $-70^{\circ} \mathrm{C}$ until needed for analysis. Standard laboratory techniques were used for the determination of serum albumin, triglycerides and total cholesterol concentrations (Abbott Clinical Chemistry). HsCRP and cytokine (IL-1 $\beta$ and IL-6) concentrations were measured by commercial, high-sensitivity sandwich enzyme-linked immunosorbent assay (ELISA) kits (DRG and BenderMed Systems, respectively).

Statistics. All analyses were performed using Statistica 7.1 (StatSoft) software. Data are presented as mean \pm S.D., unless otherwise indicated. $P<0.05$ was considered to be significant. To assess the normalcy of the distributions we used the Kolmogorov-Smirnov test. Spearman's or where appropriate Pearson's rank order correlation coefficient was used to explore the relationship between nutritional and inflammatory indices at baseline. To assess the significance of changes of the repeated measures of investigated variables either One Way ANOVA or nonparametric Friedman's ANOVA and Least Significant Differences tests (post hoc comparisons) were used, when appropriate. 


\section{RESULTS}

\section{Baseline characteristics of patients}

Forty-nine MHD and nineteen CPD of the total $381 \mathrm{MHD}$ and $89 \mathrm{CPD}$ patients were found to be eligible for the study. Thirty-four MHD and eleven CPD patients consented to participation and were enrolled in the study. Thirteen patients dropped out before the study started or within the first four weeks of the study. Nine of those subjects withdrew their consent without giving an explanation (as they were entitled to do), two underwent renal transplantation, one person died in the fourth week of the study of reasons unrelated to the study (cholangitis leading to sepsis) and one was excluded from the study because of incompliance. Their data were not included in the analysis. The analysis presented below regards 26 patients (18 MHD and 8 CPD; 13 male and 13 female) who had completed two months of megestrol acetate treatment by the end of February 2007. Mean age of the studied patients was $68.54 \pm 11.22$ years (range $38-85$ ). The causes of ESRD were: diabetic nephropathy (9), glomerulonephritis (6), polycystic kidney disease (2) and other (9).

Before the initiation of the megestrol acetate treatment we found no statistically significant cor- relation between laboratory indices of nutrition and inflammation.

\section{Nutritional indices}

All patients reported improved appetite, which was accompanied by a substantial increase in the daily energy intake. There was a concurrent increase in mean body weight and BMI after two months of treatment to $64.79 \pm 12 \mathrm{~kg}$ from the baseline of $63.59 \pm 12.38 \mathrm{~kg}$ and to $23.68 \pm 3.63 \mathrm{~kg} / \mathrm{m}^{2}$ from the baseline of $23.06 \pm 3.26 \mathrm{~kg} / \mathrm{m}^{2}$, respectively. Both changes were statistically significant $(P<0.05)$. An increase in serum albumin concentration over the intervention period from $3.51 \pm 0.33 \mathrm{~g} / 1$ to $3.659 \pm 0.449$ $\mathrm{g} / \mathrm{dl}$ was observed, and this was also statistically significant $(P=0.023$ after one month and $P=0.004$ after two months). The concentrations of total cholesterol and triglycerides decreased after two months of megestrol acetate treatment from $173.96 \pm 57.66$ $\mathrm{mg} / \mathrm{dl}$ to $165.27 \pm 57.46$ and from $146.13 \pm 75.21 \mathrm{mg} / \mathrm{dl}$ to $131.71 \pm 59.52 \mathrm{mg} / \mathrm{dl}$, respectively. These changes were insignificant (Table 1).

\section{Inflammatory indices}

There was an increase in hsCRP concentration from $7.4 \pm 5.68$ to $9.99 \pm 7.16 \mathrm{mg} / \mathrm{l}$ of borderline signif-

Table 1. Nutritional and inflammatory indices before and after 1 and 2 months of megestrol acetate administration $(n=26)$

\begin{tabular}{|c|c|c|c|c|}
\hline Variable & $\begin{array}{l}\text { Baseline (mean } \pm \text { S.D.; } \\
\text { median; } \\
\text { interquartile range) }\end{array}$ & $\begin{array}{l}1 \text { month (mean } \pm \text { S.D.; } \\
\text { median; } \\
\text { interquartile range) }\end{array}$ & $\begin{array}{l}2 \text { month (mean } \pm \text { S.D.; } \\
\text { median; } \\
\text { interquartile range) }\end{array}$ & $P$ value \\
\hline Weight $(\mathrm{kg})$ & $\begin{array}{l}63.59 \pm 12.38 \\
63.9 \\
20.4\end{array}$ & $\begin{array}{l}64.22 \pm 12.1 \\
63.75 \\
18.3\end{array}$ & $\begin{array}{l}64.79 \pm 12 \\
66.65 \\
20.0\end{array}$ & *0.049 \\
\hline BMI $\left(\mathrm{kg} / \mathrm{m}^{2}\right)$ & $\begin{array}{l}23.06 \pm 3.26 \\
22.97 \\
4.74\end{array}$ & $\begin{array}{l}23.34 \pm 3.3 \\
22.89 \\
5.2\end{array}$ & $\begin{array}{l}23.68 \pm 3.63 \\
23.08 \\
4.75\end{array}$ & ${ }^{*} 0.01$ \\
\hline Albumin (g/dl) & $\begin{array}{l}3.51 \pm 0.33 \\
3.6 \\
0.32\end{array}$ & $\begin{array}{l}3.72 \pm 0.403 \\
3.8 \\
0.3\end{array}$ & $\begin{array}{l}3.659 \pm 0.449 \\
3.75 \\
0.3\end{array}$ & $\begin{array}{l}{ }^{*} 0.023 \\
{ }^{* *} 0.004\end{array}$ \\
\hline Total cholesterol $(\mathrm{mg} / \mathrm{dl})$ & $\begin{array}{l}173.96 \pm 57.66 \\
164.0 \\
70.0\end{array}$ & $\begin{array}{l}168.42 \pm 51.85 \\
152.0 \\
55.0\end{array}$ & $\begin{array}{l}165.27 \pm 57.46 \\
153.5 \\
49.0\end{array}$ & NS \\
\hline Triglycerides (mg/dl) & $\begin{array}{l}146.13 \pm 75.21 \\
130.5 \\
93.0\end{array}$ & $\begin{array}{l}140.29 \pm 59.72 \\
127.5 \\
86.0\end{array}$ & $\begin{array}{l}131.71 \pm 59.52 \\
123.0 \\
87.0\end{array}$ & NS \\
\hline HsCRP (mg/l) & $\begin{array}{l}7.4 \pm 5.68 \\
4.8 \\
7.7\end{array}$ & $\begin{array}{l}6.99 \pm 5.74 \\
4.8 \\
8.5\end{array}$ & $\begin{array}{l}9.99 \pm 7.16 \\
13.05 \\
14.9\end{array}$ & *0.052 \\
\hline IL-1 $\beta(\mathrm{pg} / \mathrm{ml})$ & $\begin{array}{l}2.33 \pm 4.58 \\
0.0 \\
3.0\end{array}$ & $\begin{array}{l}1.91 \pm 3.18 \\
0.8 \\
2.2\end{array}$ & $\begin{array}{l}1.5 \pm 1.6 \\
1.0 \\
2.3\end{array}$ & NS \\
\hline IL-6 (pg/ml) & $\begin{array}{l}32.8 \pm 7.47 \\
26.8 \\
28.0 \\
\end{array}$ & $\begin{array}{l}39.96 \pm 8.72 \\
20.4 \\
33.5 \\
\end{array}$ & $\begin{array}{l}32.26 \pm 9.21 \\
13.8 \\
42.2 \\
\end{array}$ & NS \\
\hline
\end{tabular}

*baseline versus at 2 months; **baseline versus at 1 month 
icance. However, we did not observe any significant changes in the other biochemical markers of inflammation - IL-1 $\beta$ or IL-6 (Table 1).

\section{Side-effects}

Side-effects were common. Overhydration of varying severity or excessive fluid gain $(>4 \mathrm{~kg}$ interdialytic weight gain and/or overhydration causing pulmonary congestion and dyspnoea) between haemodialysis sessions were a problem in 9 patients, and dose reduction was required in all subjects. Excessive weight gain ( $>5 \%$ of initial body weight within four weeks) appeared in 6 subjects and in 4 of them dose reduction was necessary, while the two other patients decided to withdraw from the study. One of the diabetics required dose reduction because of hyperglycaemia, which was difficult to control with increased insulin dosage. Diarrhoea in 2 patients and nausea and vomiting in 3 subjects led to discontinuation of the megestrol acetate treatment.

\section{DISCUSSION}

Even though malnutrition is a common clinical problem and a strong predictor of cardiovascular and all-cause mortality in dialysis patients, there is still no single test that could be considered an indicator of protein-energy malnutrition. Therefore, correct assessment of nutritional status in dialysis patients is difficult. We decided to apply the most commonly used, simple and inexpensive marker of malnutrition, which is serum albumin concentration $\leq 3.8 \mathrm{~g} / \mathrm{dl}$.

The main drawback of our study is the lack of a control group. This was due to a very limited number of patients eligible for the study who consented to participate ( 26 patients out of 490 patients screened). This suggests that the actual prevalence of malnutrition among dialysis patients may have been reduced or confirms that serum albumin concentration is not a perfect malnutrition assessment tool. The former possibility is consistent with the recently published results by de Mutsert et al. (2008). In that study, three months after the start of chronic hemodialysis treatment only $10 \%$ of patients were diagnosed as being malnourished. In our study one of the inclusion criteria was maintenance dialysis treatment for at least 3 months.

So far, only six studies evaluating the use of megestrol acetate in dialysis patients have been published. Burrowes et al. (1999) published a case study of a haemodialysis patient placed on $320 \mathrm{mg} /$ day of megestrol acetate for 24 weeks. The patient reported an improvement in appetite, and his fat mass in- creased by $163 \%$, whereas his lean mass decreased by $10.6 \%$. Lien et al. (1996) placed 12 chronic peritoneal dialysis (CPD) and four maintenance hemodialysis (MHD) hypoalbuminemic patients $(<3.5 \mathrm{~g} / \mathrm{dl}$ for two consecutive months) on $20 \mathrm{mg}$ twice daily of megestrol acetate. An increase in serum albumin was seen in $75 \%$ of the patients. One patient stopped megestrol because of vaginal bleeding from leiomyoma. Boccanfuso et al. (2000) evaluated the effect of megestrol acetate suspension in 17 MHD patients with serum albumin $<3.5 \mathrm{~g} / \mathrm{dl}$ for 2 consecutive months. Four hundred milligram orally twice daily was prescribed for up to 6 months. At the end of the third month only $53 \%$ of those patients were still in the study, whereas only three of them were able to take the studied medicine for 5 to 6 months. Each of these three patients showed a positive change in nutritional status measured by subjective global assessment (SGA), appetite and caloric intake and an increase in dry weight. Side effects that led to dropout were common and included diarrhoea, confusion, headache and hyperglycaemia. Costero et al. (2004) treated 32 CPD patients with $160 \mathrm{mg}$ of megestrol acetate daily for 1-23 months and observed an increase in appetite in most patients, as well as significant weight gain with a nonsignificant increase in serum albumin. No side-effects were observed. Rammohan et al. (2005) assessed the efficacy of $400 \mathrm{mg}$ of megestrol acetate daily used for 16 weeks in nine MHD and one CPD patient. Appetite, daily energy intake, weight and serum albumin increased significantly. There was also a decrease of serum CRP of borderline significance. Quality of life was reported to be improved as well. No major side-effects were observed. Recently, Monfared et al. (2009) published results of a randomized controlled trial in a group of hypoalbuminemic haemodialysis patients. Eleven patients assigned to the experimental group were treated with $40 \mathrm{mg}$ of megestrol acetate twice daily over a period of two months, while 11 patients in the control group received their current treatment. There was a statistically significant increase in albumin concentration with concurrent changes in CRP level in the treatment group and there were no significant changes in the control group. However, the authors reported no changes in the total pre- and postdialysis weight of patients.

Our results show that administering $160 \mathrm{mg}$ of megestrol acetate suspension in hypoalbuminemic dialysis patients for a period of two months improved body weight and BMI, with a significant increase in serum albumin concentration. These findings are consistent with the results published by Rammohan et al. (2005) and partly with the results of Monfared's group (2009). Surprisingly, we observed a trend towards a decrease in total cholesterol and triglyceride levels. Costero et al. (2004) did 
not find any significant changes of cholesterol level, while Rammohan et al. (2005) showed only a statistically insignificant $1 \%$ increase.

The exact mechanisms by which megestrol acetate exerts its orexigenic effect remains unknown. It is suggested that it is likely due to down-regulation of the synthesis and secretion of proinflammatory cytokines. Hence, it was assumed that possessing both appetite-stimulating and anti-inflammatory properties would make it an optimal tool in the treatment of malnutrition or even of the MIA syndrome. However, we only observed an increase of borderline significance in hsCRP level and did not observe any significant changes in IL- $1 \beta$ or IL- 6 concentrations after megestrol acetate treatment. Similar results regarding IL-6 were observed by Jatoi et al. (2002) in a group of 85 patients with cancer-associated anorexia or weight loss.

Another issue that should be raised is the high prevalence of significant side effects resulting in the necessity to reduce the dose or to end the planned treatment prematurely. This was especially surprising as the $160 \mathrm{mg}$ dose we decided to use has been described to be safe and associated with no adverse events (Costero et al., 2004). It is even more difficult to explain the lack of side-effects when using higher doses of megestrol acetate (Rammohan et al., 2005).

In conclusion, megestrol acetate may be an effective therapeutic agent in reversing poor appetite in carefully selected maintenance dialysis patients. Our limited experience suggests that it might not mitigate inflammation or improve the quality of life, but our ongoing study should clarify this issue. Because of the prevalent side effects its use must be monitored closely. Perhaps tailoring the dosage according to individual response would solve some megestrol-related problems. Further studies are needed to learn whether benefits of megestrol acetate would outweigh the side effects.

\section{Acknowledgements}

Supported by the Ministry of Science and Higher Education grant No. N 402007 32/0121.

\section{REFERENCES}

Boccanfuso JA, Hutton M, McAllister B (2000) The effects of megestrol acetate on nutritional parameters in a dialysis population. J Ren Nutr 10: 36-43.

Burrowes JD, Bluestone PA, Wang J, Pierson RN Jr (1999) The effects of moderate doses of megestrol acetate on nutritional status and body composition in a hemodialysis patient. J Ren Nutr 9: 89-94.

Costero O, Bajo MA, del Peso G, Gil F, Aguilera A, Ros S, Hevia C, Selgas R (2004) Treatment of anorexia and malnutrition in peritoneal dialysis patients with megestrol acetate. Adv Perit Dial 20: 209-212.

de Mutsert R, Grootendorst DC, Axelsson J, Boeschoten EW, Krediet RT, Dekker FW and the NECOSAD Study Group (2008) Excess mortality due to interaction between protein-energy wasting, inflammation and cardiovascular disease in chronic dialysis patients. Nephrol Dial Transplant 23: 2957-2964.

Dwyer JT, Larive B, Leung J, Rocco M, Burrowes JD, Chumlea, Frydrych A, Kusek JW, Uhlin L, HEMO Study Group (2002) Nutritional status affects quality of life in hemodialysis (HEMO) study patients at baseline. J Ren Nutr 12: 213-223.

Jatoi A, Yamashita J, Sloan JA, Novotny PJ, Windschitl HE, Loprinzi CL (2002) Does megestrol acetate downregulate interleukin-6 in patients with cancer-associated anorexia and weight loss? A North Central Cancer Treatment Group investigation. Support Care Cancer 10: 71-75.

Kalantar-Zadeh K, Ikizler A, Block G, Avram M, Kopple J (2003) Malnutrition-inflammation complex syndrome in dialysis patients: causes and consequences. Am J Kidney Dis 42: 864-881.

Kalantar-Zadeh K, Kilpatrick RD, Kuwae N, McAllister CJ, Alcorn H Jr, Kopple JD, Greenland S (2005) Revisiting mortality predictability of serum albumin in the dialysis population: time dependency, longitudinal changes and population-attributable fraction. Nephrol Dial Transplant 20: 1880-1888.

Kalantar-Zadeh K, Kopple J, Block G, Humphreys M (2001) Association among SF36 quality of life measures and nutrition, hospitalization, and mortality in hemodialysis. J Am Soc Nephrol 12: 2797-2806.

Lien YH, Ruffenach SJ (1996) Low dose megestrol increases serum albumin in malnourished dialysis patients. Int $J$ Artif Organs 19: 147-150.

Lopez AP, Figuls MR, Cuchi GU, Berenstein EG, Pasies BA, Alegre MB, Herdman M (2004) Systematic review of megestrol acetate in the treatment of anorexia-cachexia syndrome. J Pain Symptom Manage 27: 360-369.

Mantovani G, Maccio A, Lai P, Massa E, Ghiani M, Santona MC (1998a) Cytokine activity in cancer-related anorexia/cachexia: role of megestrol acetate and medroxyprogesterone acetate. Semin Oncol 25: 45-52.

Mantovani G, Maccio A, Lai P, Massa E, Ghiani M, Santona MC (1998b) Cytokine involvement in cancer anorexia/cachexia: role of megestrol acetate and medroxyprogesterone acetate on cytokine downregulation and improvement of clinical symptoms. Crit Rev Oncolog 9: 99-106.

Monfared A, Heidarzadeh A, Ghaffari M, Akbarpour M (2009) Effect of megestrol acetate on serum albumin level in malnourished dialysis patients. J Ren Nutr 19: 167-171.

Murtagh FE, Addington-Hall J, Higginson IJ (2007) The prevalence of symptoms in end-stage renal disease: a systematic review. Adv Chronic Kidney Dis 14: 82-99.

Rammohan M, Kalantar-Zadeh K, Liang A, Ghossein C (2005) Megestrol acetate in a moderate dose for the treatment of malnutrition-inflammation complex in maintenance dialysis patients. J Ren Nutr 15: 345-355.

Rashid Qureshi A, Alvestrand A, Divino-Filho JC, Gutierrez A, Heimbürger O, Lindholm B, Bergström J (2002) Inflammation, malnutrition, and cardiac disease as predictors of mortality in hemodialysis patients. J Am Soc Nephrol 13: S28-S36. 